\title{
EDUCAÇÃO A DISTÂNCIA: O COMBATE À VIOLÊNCIA DOMÉSTICA CONTRA CRIANÇAS E ADOLESCENTES - UMA EXPERIÊNCIA BEM SUCEDIDA
}

\author{
Maria Amélia Azevedo* \\ Viviane Nogueira de Azevedo Guerra \\ Abrão Bernardo Zweiman" \\ Eiko Nishizawa ${ }^{\mathfrak{x}}$
}

\begin{abstract}
RESUMO. Trata-se de relato de experiência em educação a distância, em cursos na área da VIOLÊNCIA DOMÉSTICA contra Crianças e Adolescentes, em nível de especialização (pós-graduação Lato Sensu), promovidos pelo Laboratório de Estudos da Criança do Instituto de Psicologia da Universidade de São Paulo. Foi planejado para deixar trilhas em cada comunidade e região considerando que os egressos e as gerações futuras de telealunos darão continuidade ao projeto social em curso.
\end{abstract}

Palavras-chave: educação a distância, experiência.

\section{DISTANCE LEARNING: FIGHTING DOMESTIC VIOLENCE AGAINST CHILDREN AND ADOLESCENTS - A SUCCESSFUL EXPERIENCE}

\begin{abstract}
It is an account of the experience in Distance Learning in courses in the area of Domestic Violence against Children and Adolescents, at specialization level (post-graduation, latu senso), promoted by the Child Studies Laboratory of the Psychology Institute of the University of São Paulo. It was planned to leave tracks in every community and region by considering that the egressed students and the future generations of tele-students will give continuity to the social project of the course.
\end{abstract}

Key words: distance learning, experience.

\section{INTRODUÇÃO}

Nunca está nada concluído, meu rapaz.

O passado explica o presente.

Por exemplo, por que o sistema educacional é o que é? (Asimov, 1973).

A educação a distância assume a cada dia função de maior importância, em especial, no ensino superior, com as demandas educacionais cada vez maiores, e que não podem ser atendidas nas modalidades tradicionais de ensino, e com a busca de formação contínua, gerada pela desatualização acelerada da tecnologia e do conhecimento.

Estudiosos da educação a distância debatem esta problemática complexa, buscando responder perguntas, tais como: o que é a educação a distância dentro da realidade educacional? Quais os desafios que ela coloca? Em que direção ela caminha?

$\mathrm{Na}$ década de oitenta, duas orientações teóricas contrapõem-se e/ou coexistem na educação em geral e na educação a distância em particular - o estilo fordista de

\footnotetext{
Doutora, Professora Titular do Instituto de Psicologia da USP, Coordenadora do Laboratório de Estudos da Criança (LACRI).

\# Mestre e Doutora em Serviço Social. Pesquisadora do LACRI

Endereço para correspondência: LACRI, Av. Prof. Mello Morais, 1721, Cidade Universitária, São Paulo - SP. CEP 05508-900. E-mail: lacri@sti.com.br

II Diretor das Faculdades Integradas Hebraico-Brasileiras Renascença, orientador Pedagógico do LACRI/IPUSP

æ Orientadora Pedagógica do LACRI/IPUSP.
} 
educação em massa e uma proposta mais direta e flexível que tenta responder às novas exigências sociais.

A educação aberta e a distância, com potencialidades globais, ao mesmo tempo em que se transforma numa nova mercadoria, passa também a exigir do aluno motivação, autonomia para estudar e administrar o seu tempo, competências que talvez não estejam desenvolvidas nos adultos que a procuram. Este é um panorama recente que, para se consolidar, necessita urgentemente de mudanças na educação geral e no ensino superior, assim como de pesquisas que ampliem o conhecimento sobre o processo de aprendizagem do adulto, propiciando o desenvolvimento de metodologias de ensino mais atuais.

Gutiérrez \& Prieto (1994) propõem uma educação a distância transformadora cujo discurso pedagógico seja mediado para que a educação recupere a sua significação para professores e estudantes. Entendem por mediação pedagógica "os tratamentos do conteúdo e as formas de expressão dos diferentes temas, a fim de tornar possível o ato educativo". Ressaltam que no sistema de educação a distância, ela atinge o seu maior grau de importância considerando que "são os materiais que permitem ao estudante encontrar e concretizar o sentido do processo educativo".

De acordo com as experiências desses autores, um sistema de educação a distância terá que preencher as seguintes características:

- ser participativo apesar da distância;

- partir da realidade e fundamentar-se na prática social do estudante;

- promover atitudes críticas e criativas nos agentes do processo (educador-educando);

- abrir caminhos para a expressão e a comunicação;

- promover processos e obter resultados;

- fundamentar-se na produção de conhecimentos;

- desenvolver no aluno uma atitude investigativa.

A experiência que relataremos a seguir orientouse por essas diretrizes.

\section{A VIOLÊNCIA DOMÉSTICA EM QUESTÃO NO BRASIL}

Um obstáculo de "natureza científica" importante, no que respeita à prevenção da Violência Doméstica contra Crianças e Adolescentes, é a quase universal precariedade do monitoramento epidemiológico do fenômeno. Segundo Finkelhor (1999), "necessitamos de bons dados epidemiológicos a fim de identificarmos localização e fonte do problema do abuso infantil (child abuse) e também para conseguirmos rastrear e monitorar nossos esforços".

O Laboratório de Estudos da Criança/Instituto de Psicologia da USP (LACRI) vem tentando suprir essa lacuna, realizando anualmente levantamentos "possibilísticos"1 sobre "incidência" das várias modalidades de Violência Doméstica contra Crianças e Adolescentes em diferentes Municípios e Estados do Brasil e no Peru.

A expectativa é a de que a médio prazo seja possível traçarmos um perfil aproximado do que consideramos A "ponta do iceberg", de violências domésticas cotidianamente praticadas contra crianças e adolescentes e denunciadas a instituições de atenção à infância.

A Tabela 1 mostra os resultados cumulativos até 2000 .

Tabela 1. Violência Doméstica contra Crianças e Adolescentes (VDCA) (notificada no Brasil).

\begin{tabular}{lcccccc}
\hline $\begin{array}{l}\text { Modalidade de } \\
\text { VDCA }\end{array}$ & $\mathbf{1 9 9 6}$ & $\mathbf{1 9 9 7}$ & $\mathbf{1 9 9 8}$ & $\mathbf{1 9 9 9}$ & $\mathbf{2 0 0 0}$ & $\begin{array}{c}\text { Número total de } \\
\text { casos notificados }\end{array}$ \\
\hline Violência Física & 525 & 1.240 & 2.804 & 2.620 & 4.330 & 11.519 \\
Violência Sexual & 95 & 315 & 578 & 647 & 978 & 2.613 \\
Violência Psicológica & 0 & 53 & 2.105 & 893 & 1.493 & 4.544 \\
Negligência & 572 & 456 & 7.148 & 2.512 & 4.205 & 14.893 \\
Violência Fatal & 0 & 0 & 0 & 0 & 135 & 135 \\
\hline Total & $\mathbf{1 . 1 9 2}$ & $\mathbf{2 . 0 6 4}$ & $\mathbf{1 2 . 6 3 5}$ & $\mathbf{6 . 6 7 2}$ & $\mathbf{1 1 . 1 4 1}$ & $\mathbf{3 3 . 7 0 4}$ \\
\hline
\end{tabular}

Pela leitura destes dados podemos observar que:

- houve um crescimento de notificações de 1996 a 2000, especialmente no que tange a casos de violência física e sexual;

- quanto à negligência houve oscilação, ou seja, anos em que as notificações subiram muito, decrescendo posteriormente;

- a violência fatal apareceu mais recentemente, uma vez que este dado não era colhido em anos anteriores a 2000 ;

- até mesmo a violência psicológica, tão difícil de detectar, foi surgindo nestas estatísticas;

- ao se verificar o número total de casos notificados em todos esses anos (1996 a 2000), pode-se observar que a negligência ocupou o primeiro lugar, seguida pela violência física e por aquela de natureza psicológica.

Ao analisarmos estes dados podemos inferior que:

- estamos tratando com um fenômeno bem significativo em nossa sociedade;

1 Tais levantamentos não são aleatórios, já que realizados por telestudantes LACRI em instituições de seus próprios municípios de origem, através de instrumento padronizado (e pré-testado) de coleta de dados. 
- a luta por sua prevenção deve ser uma tarefa contínua, especialmente porque inúmeras de suas modalidades podem trazer como consequiência a morte para suas vítimas. Uma das modalidades, aliás bem preocupante, é a violência física e que pelo comportamento de nossas estatísticas é bem representativa em nosso meio. Partindo-se do pressuposto de que toda ação que atinge o corpo de uma criança, em seu processo de disciplinamento, é e deve ser considerada como violência, observamos que se não lutarmos para abolir a punição corporal em nosso meio, a violência física continuará se incrementando no Brasil. Aliás, consultando-se o documento World Perspectives on Child Abuse C $^{3}$ - 2000, pode-se observar que em $24.6 \%$ dos países que participam desta investigação, entre 76 e $100 \%$ dos pais disseram utilizar a punição corporal em termos de seus filhos, enquanto que em menos do que $10 \%$ dos países, menos do que $25 \%$ dos pais usam tal prática. Isto é simplesmente assustador tendo em vista que a aceitação da punição corporal doméstica é muito grande em termos mundiais, devendo, portanto, incrementar-se não só em termos brasileiros, mas mundiais, a luta que priorize o combate a esta prática ${ }^{4}$.

- a violência sexual que aparece como uma modalidade menos relevante na verdade pode ter índices bem superiores uma vez que é um dos fenômenos mais escondidos nas estatísticas não só brasileiras como mundiais pelo complô de silêncio que usualmente a cerca;

- a violência psicológica que mais recentemente nos anos 90 tem chamado a atenção de pesquisadores da área aparece nestas estatísticas e convoca os pesquisadores à realização de estudos mais consistentes sobre ela em nosso meio, uma vez que os traumas dela decorrentes são considerados bem significativos;

- finalmente a presença da violência fatal tem o seu forte impacto na medida que revela que está na hora de uma revisão ampla de nossas políticas de proteção à infância e à adolescência vítimas de

3 Este documento foi preparado pelo Kempe Children's Center, University of Colorado School of Medicine e é uma publicação oficial da International Society for Prevention of Child Abuse and Neglect. Foi o $4^{\circ}$ documento de uma série estatística mundial sobre o fenômeno da Violência Doméstica contra Crianças e Adolescentes e apresentado no XIII Congresso Internacional sobre este tema em Durban, África do Sul, setembro de 2000. Cerca de 58 países enviaram informes para a composição deste documento.

4 Ressalte-se que em 8 países do mundo já é proibido o uso da punição corporal doméstica contra crianças e adolescentes (Suécia, Finlândia, Noruega, Dinamarca, Áustria, Chipre, Letônia, Croácia). violência doméstica uma vez que este tipo de violência é o resultado de um combate nítido, não capacitado, não enfocado na prevenção e na detecção precoce em nosso meio.

Portanto, as estatísticas frias com seus números devem ser bem analisadas pois podemos perceber que através delas é preciso uma ampla revisão do trabalho que vem sendo feito nesta área para que se reduzam os casos de violência doméstica dirigidos a crianças e adolescentes.

Outros obstáculos à prevenção merecem comentários especiais. É o caso, por exemplo, da famosa hierarquização entre os problemas da "infância em dificuldade". Segundo essa visão falaciosa, "a infância pobre" seria "mais importante" que a "infância vitimizada" no lar e mereceria, portanto, uma atenção privilegiada. É fácil entender que essa grosseira mistificação tem a ver com o diferencial de visibilidade das duas problemáticas.

O outro grande obstáculo é o que poderíamos chamar de Síndrome do S.O.S.: em vez de uma focalização prioritária na "prevenção primária", a ênfase recai quase sempre nos níveis secundário e terciário. Sem negar a importância destes últimos, o LACRI tem defendido a postura de que "é preciso chegar antes que uma criança se torne um prontuário médico, um boletim policial, um processo judicial, um dossiê psicossocial, uma notícia de jornal ou um corpo no necrotério". Coerente com esse lema, desenvolveu um "original programa de prevenção primária da Violência Doméstica contra Crianças e Adolescentes", assentado na "sinergia entre pesquisa, capacitação profissional e conscientização comunitária”. Trata-se de um Curso de Educação Continuada a Distância, o Telecurso de Especialização na Área da Violência Doméstica contra Crianças e Adolescentes (TELELACRI). Em seu oitavo ano de existência, o TELELACRI tem as características inovadoras que vão brevemente enunciadas a seguir:

\section{a. Estrutura}

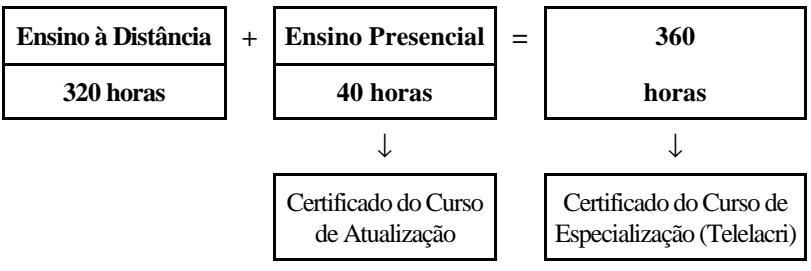

Trata-se de um curso de Educação Continuada a Distância (ECAD), ministrado em nível de especialização (pós-graduação Lato Sensu).

O TELELACRI envolve obrigatoriamente duas partes: 
- Uma, de Ensino a Distância.

- Outra, de Ensino Presencial, compreendendo um Curso de Atualização, sempre com a participação de profissionais brasileiros e/ou estrangeiros, atuando em parceria com a Equipe Lacri.

Utilizando uma tecnologia simples, que é a divisão de todo o material teórico referente ao Telecurso em módulos progressivos e planejados com base no modelo Mastery Learning, enviados pelo correio aos telealunos que, por sua vez, devem efetuar a sua leitura dentro de um calendário pré-programado e debatido em conjunto com sua equipe. Tarefas são exigidas durante o Telecurso, a partir de cujos relatórios é possível à sua Supervisão acompanhar o grau de aprendizagem e de entendimento da temática desenvolvida. Como suporte e retaguarda, a Supervisão acompanha e atende a todos os telealunos, organizados em equipes nos municípios onde residem, solucionando dúvidas, orientando e esclarecendo sobre o cumprimento das tarefas propostas, por meio de atendimento telefônico, via faz ou via e-mail.

Através de site na Internet, informações são disponibilizadas, tais como: leituras complementares, questionários e pesquisas que podem ser acessados pelos telealunos para complementação de suas tarefas e estudos.

\section{b. Perfil}

Seu perfil inclui as seguintes características básicas:

- Individualizado: possibilitando que cada telealuno(a) "estude" e progrida no seu próprio ritmo;

- Interativo: favorecendo a troca de informações, dúvidas etc., entre Coordenação e telealunos e entre telealunos de ontem e de hoje, criando redes de comunicações em circuito aberto, operadas a partir da USP (via fax, fone, e-mail);

- Multimídia: tendo em vista que os materiais instrucionais, elaborados para o Telecurso, envolvem mídia impressa (Módulos apostilados), audiocassetes, videocassetes e Internet;

- Sinérgico: seu conteúdo, como o próprio nome indica, é o da problemática da Violência Doméstica contra Crianças e Adolescentes, escolhida em função da necessidade crescente de capacitar profissionais para atuarem eficazmente no combate a esse tipo de abuso. Assim sendo, em vez de ser apenas uma forma de enriquecer currículos pessoais é, antes de tudo, uma estratégia de combate a um grave problema social através de um estilo peculiar de luta: Sinergia entre Pesquisa, Capacitação e Conscientização Comunitária.

- Tipo 2 em 1: ao concluir satisfatoriamente o Telelacri, o aluno terá direito a dois certificados: Especialização + Atualização.

Tratando-se de modalidade rara, no âmbito do ensino universitário brasileiro e praticamente inédito na área da Violência Doméstica contra Crianças e Adolescentes, é preciso ter certeza também acerca do que essa iniciativa não é, a fim de não nutrir falsas esperanças a seu respeito. Assim, o Telecurso não é:

- ensino por correspondência;

- ensino pela TV;

- ensino de base telemática;

- ensino de segunda classe;

- pós-graduação Stricto Sensu;

- empreendimento burocrático cartorial.

Nesse sentido, não é um curso ornamental, de fazde-conta, envolvendo tarefas vicárias, virtuais. É um Curso planejado para deixar trilhas em cada comunidade ou região, cujos egressos darão continuidade ao projeto social do Curso e que estarão sendo retomadas e ampliadas por gerações futuras de telealunos.

Seus resultados têm sido bastante encorajadores sob os mais variados ângulos:

- Do ponto de vista acadêmico: de 1994 a 2000, capacitaram-se 2.348 telestudantes no Brasil e no Peru. O grau de aproveitamento, ano a no, tem sido mais do que satisfatório ${ }^{6}$.

- Do ponto de vista científico: foram concluídos cinco amplos projetos de pesquisa, estando um deles em curso. A maioria foi publicada ou está no prelo, envolvendo em dois deles, projetos editoriais multimídia (livro e vídeo) ${ }^{7}$.

- Do ponto de vista de conscientização comunitária: 9.678 participantes nos debates conscientizadores promovidos pelos telestudantes no Brasil e no exterior (Peru), nos anos de 1999 e 2000, envolvendo a discussão em suas respectivas comunidades, das modalidades física e fatal da

6 No ano de 2000, de um total de 648 telestudantes: $88 \%$ foram aprovados; $3 \%$ deles desistiram; $4 \%$ foram reprovados; $5 \%$ ficaram com o curso incompleto.

7 Consulte-se: Azevedo \& Guerra (1998); Crônicas de morte anunciada (Vídeo,1999); Azevedo \& Guerra (2001) e Vozes da Infância - a palmada deseduca, (Vídeo, 2001). 
Violência Doméstica contra Crianças e Adolescentes ${ }^{8}$.

- Do ponto de vista cultural: os telestudantes têm produzido inúmeros materiais de prevenção da problemática da Violência Doméstica contra Crianças e Adolescentes (folders, clips, banners, livretos, guias, jogos, páginas para Internet, adesivos, bottons etc.). Tais materiais costumam ser utilizados em programas locais de prevenção em escolas, hospitais, creches etc.

- Do ponto de vista pessoal: o TELELACRI tem ajudado os alunos a se libertarem de suas "reticências psicológicas" no trato da questão da Infância e Violência Doméstica, a fim de poderem ser os melhores advogados da criança.

Desta forma, um dos principais objetivos da Educação a Distância, preconizados na Lei de Diretrizes e Bases n. 9.394/96, torna-se viável e atingível, ou seja, o de garantir uma educação continuada e assistida, na qual o aluno continua sendo o centro do processo de aprendizagem, estimulado a desenvolver habilidades independentes, tomada de decisões, responsabilidade, esforço e dedicação, devendo selecionar ele mesmo as informações, as reflexões no processo de tomada de decisões. A figura do professor se transforma num orientador fisicamente não presente e que acaba, por suas intervenções, se tornando um agente facilitador da aprendizagem.

As evidências inequívocas sobre a importância estratégica do TELELACRI para a prevenção da violência doméstica contra crianças e adolescentes, enquanto modalidade de educação continuada a distância, permitem prever que, já nesse milênio, o combate à "cultura do terror", de que nos fala Galeano (1997), será mais e mais ampliado, a fim de que "os direitos humanos possam realmente começar em casa".

\begin{abstract}
A Cultura do Terror
A extorsão, o insulto, a ameaça, o cascudo, a bofetada, a surra, o açoite, o quarto escuro, a ducha gelada, o jejum obrigatório, a comida obrigatória, a proibição de sair, a proibição de dizer o que se pensa, a proibição de fazer o que se sente, e a humilhação pública são alguns dos métodos de penitência e tortura
\end{abstract}

\footnotetext{
Desde 1994, o LACRI vem conduzindo a campanha $A$ Palmada Deseduca, cuja peça chave tem sido a "Petição por uma Pedagogia Não Violenta", assinada até março de 2001 por 104.000 pessoas no Brasil e no Peru. Consulte-se a respeito: www.usp.br/ip/laboratorios/lacri e www.renascenca.br/faculdade/lacri-usp.
}

tradicionais na vida da família. Para castigo à desobediência e exemplo de liberdade, a tradição familiar perpetua uma cultura de terror que humilha a mulher, ensina os filhos a mentir e contagia tudo com a peste do medo. Os direitos humanos deveriam começar em casa, comenta comigo, no Chile, Andrés Domingues (Galeano, 1997).

\section{Referências Bibliográficas}

Azevedo, M.A. \& Guerra, V.N.A. (2001). Mania de bater - a punição corporal doméstica de crianças e adolescentes no Brasil. São Paulo: Iglu.

Azevedo, M.A. \& Guerra, V.N.A. (1998). Infância e violência fatal em família: primeiras aproximações ao nível de Brasil. São Paulo: Iglu.

Asimov, I. (1973). Nove amanhãs. Rio de Janeiro: Expressão e Cultura.

Crônicas de morte anunciada (1999). Lacri. Video.

Finkelhor, D. (1999). The science. Child Abuse and Neglect, 23(10): 964-74.

Galeano, E. (1997). O livro dos abraços. $6^{\mathrm{a}}$ ed. Porto Alegre: L\&PM.

Gutiérrez, F. \& Prieto, D. (1994). A mediação pedagógica. Campinas, Sp: Papirus.

Vozes da Infầncia - a palmada deseduca. (2001) Lacri/Núcleo de Cinema de Animação de Campinas. Vídeo.

Recebido em 30/05/2001

Revisado em 08/06/2001 Aceito em 29/06/2001 
